\title{
AIDS-Associated Pediatric High Grade B-cell Lymphoma with MYC and BCL2 Translocations
}

Msimang MZ1, Ramdial PK ${ }^{1 *}$, Kuppusamy JB ${ }^{1}$, Nargan $\mathrm{K}^{2}$ and Mohamed H Sheik-Gafoor ${ }^{3}$

${ }^{1}$ Department of Anatomical Pathology, National Health Laboratory Service and University of KwaZulu-Natal, Durban, South Africa

${ }^{2}$ Africa Health Research Institute, Durban, KwaZulu-Natal, South Africa

${ }^{3}$ Department of Paediatric Surgery, Nelson R. Mandela School of Medicine, University of KwaZulu-Natal, Inkosi Albert Luthuli Central Hospital, Durban, KwaZulu-Natal,

South Africa

\begin{abstract}
"Double hit" lymphomas (DHLs) are now included as a distinct entity in the 2016 revised World Health Classification of lymphoid neoplasms under the rubric "High-grade B-cell lymphoma (HGBCL), with MYC and BCL2 and/or BCL6 translocations". While DHL/HGBCL with MYC and BCL2 translocations accounts for approximately $10 \%$ of all lymphomas with the phenotypic and immunophenotypic features of diffuse large B-cell lymphoma (DLBCL), to date, the entity is unreported in children $<12$ years and in patients with AIDS. In reporting a DHL/HGBCL with MYC and BCL2 translocations in a 10 year old boy, we contextualize, for the first time, its occurrence and clinicopathological profile in the context of pediatric HIV infection and AIDS. In so doing, the defining features of DHL/ HGBCL with MYC and BCL2 translocations in the updated 2016 WHO classification are discussed. In addition, the clinicopathological features and therapeutic approaches in children and adults and related challenges thereof, are highlighted. Finally, the spectrum of AIDS-associated lymphomas in children and adults are tabulated and the associated diagnostic and therapeutic challenges are addressed briefly.
\end{abstract}

Keywords: AIDS; Pediatric; Lymphoma; Double hit; Translocations; $M Y C ; B C L 2$

\section{Introduction}

"Double hit" lymphomas (DHLs) are now included in the 2016 revised World Health Classification of lymphoid neoplasms under the rubric "High-grade B-cell lymphoma (HGBCL), with $M Y C$ and $B C L 2$ and/or BCL6 translocations" [1]. Despite the classification re-dress and revised label, DHLs/HGBCLs with MYC and BCL2 translocations remain an emerging entity and a challenging malignancy devoid of a standard-of-care treatment [2]. Originally regarded as an uncommon malignancy that accounted for $<1 \%$ of all lymphomas, more recent systematic investigations of $M Y C$ and $B C L 2$ abnormalities have demonstrated that DHL/HGBCL with MYC and BCL2 translocations is an underestimated malignancy. Currently DHL/HGBCL with MYC and BCL2 translocations accounts for approximately $10 \%$ of all lymphomas with the phenotypic and immunophenotypic features of diffuse large B-cell lymphoma (DLBCL) $[3,4]$. Demographically, DHL/HGBCL with $M Y C$ and BCL2 translocations occurs in older patients, with a predominant age range of 51 to 65 years and a slight male bias $[1,3,4]$. They are rare in children, adolescents and young adults [5]. To date, to the best of our knowledge, HGBCL with MYC and BCL2 translocations, is not only undocumented in the global literature in patients younger than 12 years, but are also unreported in children with AIDS.

In reporting a DHL/HGBCL with $M Y C$ and $B C L 2$ translocations in a 10 year old boy, we not only expand the global clinicopathological database of this emerging hematolymphoid entity, but also document, for the first time, its occurrence and clinicopathological profile in the context of pediatric HIV infection and AIDS. In so doing, we discuss issues addressed by the updated 2016 WHO classification on DHL/ HGBCL with $M Y C$ and BCL2 translocations, the clinicopathological features in children and adults and the therapeutic approaches and challenges thereof. In addition, we briefly describe the spectrum of AIDS-associated lymphomas in children and adults and report on the associated diagnostic and therapeutic challenges.

\section{Case Report}

\section{Clinical features}

A 10 year old boy presented initially to a surgical outpatient unit with a 2 month history of chronic gastroenteritis and fecal incontinence. He was known to be HIV-seropositive on highly active anti-retroviral therapy (HAART) (abacavir, lamivudine, efavirenz), and virally suppressed with a CD4 count of 590 cells/L. The patient had also completed treatment for pulmonary tuberculosis. On clinical examination he had bilateral cervical lymphadenopathy, a suprapubic abdominal mass and a large friable rectal mass that was biopsied. The histopathological appraisal and work-up confirmed DLBCL. Subsequent staging CT scan and bone marrow studies excluded central nervous system (CNS) and bone marrow disease. The patient had successful clinical remission following intensive treatment with high dose methotrexate, cyclophosphamide and doxorubicin based on the Berlin-Frankfurt-Münster (BFM) protocol.

A recurrence was detected six months later. Restaging confirmed the absence of CNS or bone marrow involvement. The patient was still virally suppressed but the CD4 count had dropped to 156 cells/ $\mu \mathrm{L}$. The patient was commenced on salvage therapy with rituximab, cyclophosphamide, doxorubicin and methotrexate but developed severe pancytopenia. Following 8 weeks of patient stabilization, an

*Corresponding author: PK Ramdial, Department of Anatomical Pathology, Leve 3, Laboratory Building, Inkosi Albert Luthuli Central Hospital, 800 Vusi Mzimela Road, Mayville, 4058, KwaZulu-Natal, South Africa; Tel: +27 (0)31 2402693; Fax: + 27 (0)31 2402610; E-mail: ramdial@ukzn.ac.za; ramdialpk@gmail.com

Received October 23, 2017; Accepted November 01, 2017; Published November 08, 2017

Citation: Msimang MZ, Ramdial PK, Kuppusamy JB, Nargan K, Sheik-Gafoor MH (2017) AIDS-Associated Pediatric High Grade B-cell Lymphoma with MYC and BCL2 Translocations. J AIDS Clin Res 8: 742. doi: 10.4172/2155-6113.1000742

Copyright: (c) 2017 Msimang MZ, et al. This is an open-access article distributed under the terms of the Creative Commons Attribution License, which permits unrestricted use, distribution, and reproduction in any medium, provided the original author and source are credited. 
Citation: Msimang MZ, Ramdial PK, Kuppusamy JB, Nargan K, Sheik-Gafoor MH (2017) AIDS-Associated Pediatric High Grade B-cell Lymphoma with MYC and BCL2 Translocations. J AIDS Clin Res 8: 742. doi: 10.4172/2155-6113.1000742

Page 2 of 7

anterior colonic resection with colo-anal anastomosis and covering ileostomy was successfully undertaken, but the patient developed sepsis and required a relaparotomy for resection of necrotic colonic tissue. On recovery he received radiotherapy and further chemotherapy, but responded poorly and demised from multi-organ failure.

\section{Pathological features}

Gross features: The lower anterior resection specimen measured $38 \times 8 \mathrm{~cm}$ (Figure $1 \mathrm{~A}$ ) and contained a $14 \times 9 \times 7 \mathrm{~cm}$ exophytic, creamwhite, fleshy tumor (Figure 1B) with hemorrhagic foci, $12 \mathrm{~cm}$ and 3 $\mathrm{cm}$ from the proximal and distal excision margins, respectively. The proximal and circumferential resection margins were tumor-free. The microscopic findings confirmed an ulcerative, invasive malignancy with transmural involvement and a diffusely infiltrative pattern (Figure 1C). The pleomorphic tumor cells were large with scant eosinophilic cytoplasm, indistinct cell borders and large, vesicular nuclei with distinctive nuclear membranes and prominent nucleoli (Figure 1D). Brisk mitotic activity was evident. Immunohistochemically, there was bright and diffuse CD45 (Figure 2A), CD20 (Figure 2B), BCL2 (Figure 2C), BCL6 (Figure 2D) and CD10 (Figure 2E) immunopositivity. In addition, there was patchy MUM-1 (Figure $3 \mathrm{~A}$ ) and approximately $60 \%$, variable nuclear and cytoplasmic C-MYC immunopositivity (Figure 3B) and a Ki-67 proliferation index of $>90 \%$ (Figure 3C). T-lymphocyte and terminal deoxynucleotidyl transferase immunomarkers were negative. Epstein Barr virus (EBV)-encoded small RNA (EBER) positivity (Figure 3D) was confirmed on chromogen in-situ hybridization investigation. Fluorescent in-situ hybridization studies demonstrated $\mathrm{IgH}-\mathrm{cMYC}[\mathrm{t}(8$; 14)] (Figure 4A) and $I g H-B C L 2[\mathrm{t}(14 ; 18)]$ (Figure 4B) translocations. $B C L 6$ and cyclin D1 translocations were not observed.

\section{Discussion}

Improved insight into and major advances in the genetic/molecular landscape of malignant lymphomas have necessitated revision of the 2008 WHO classification of hematopoietic and lymphoid tumors and its related monograph. There are no new distinctive entities in the 2016 revised $4^{\text {th }}$ edition of the WHO classification but a few provisional entities have been introduced, and some provisional entities have been promoted as definite entities; DHL/HGBCL with MYC and $B C L 2$ translocations is included in the latter group. The $2008 \mathrm{WHO}$ classification heralded the category of ' $\mathrm{B}$-cell lymphoma, unclassifiable' (BCLU), with features intermediate between DLBCL and Burkitt lymphoma (BL). BCLUs emerged as very aggressive lymphomas with a gene expression profile intermediate between positively and negatively molecularly profiled $\mathrm{BL}$, and a mutational profile intermediate between that of DLBCL and BL [1]. Hence, the re-categorization of DHL in the 2016 WHO update as "HGBL, with MYC and BCL2 and/ or BCL6 rearrangements" is attributed to heightened $M Y C$ analyses in DLBCLs [1,6,7], improved immunophenotypic understanding of the histogenesis of DLBCLs $[1,8]$ and refinement of the DHL phenotypic, immunophenotypic and genotypic landscape.

The 2016 WHO update has aided the diagnosis and dialogue of DHL/HGBL, with MYC and BCL2 and/or BCL6 rearrangements in several aspects, viz.:

- Exclusion of the BCLU category because of vague diagnostic criteria and resultant inconsistent application,

- Exclusion of cases with the morphological features of follicular and lymphoblastic lymphoma, and,

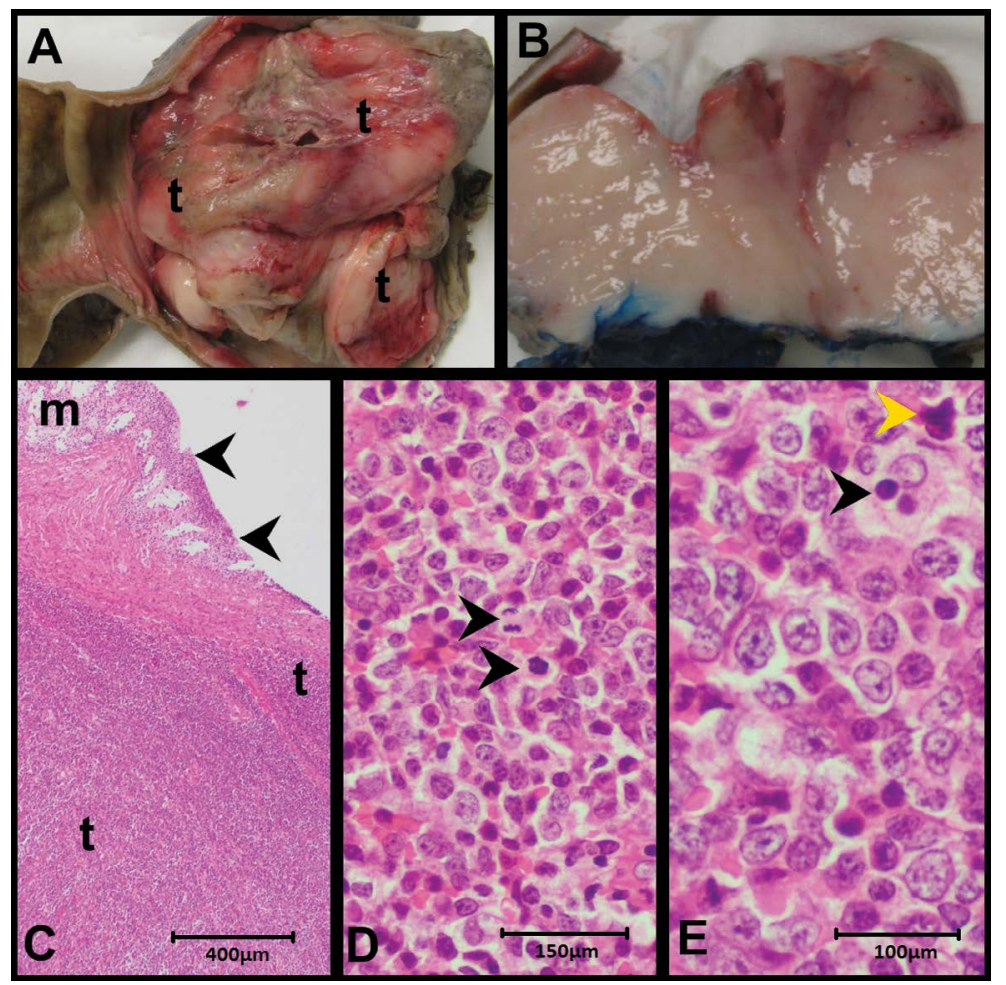

Figure 1: Gross and microscopic features: Lower anterior resection highlighting tumor filling rectum (A) with a solid, fleshy appearance on cut section (B). Hematoxylin and eosin stained sections of the ulcerated (C, arrowheads) rectal tumor (t) extending transmurally. Medium power (D) depiction of a dense, mitotically active (arrowheads), cellular, high grade tumor. High power (E) characterization of cells with centroblastic and immunoblastic features, apoptotic bodies (yellow arrowhead) and tingible body macrophages (black arrowhead). 
Citation: Msimang MZ, Ramdial PK, Kuppusamy JB, Nargan K, Sheik-Gafoor MH (2017) AIDS-Associated Pediatric High Grade B-cell Lymphoma with MYC and BCL2 Translocations. J AIDS Clin Res 8: 742. doi: 10.4172/2155-6113.1000742

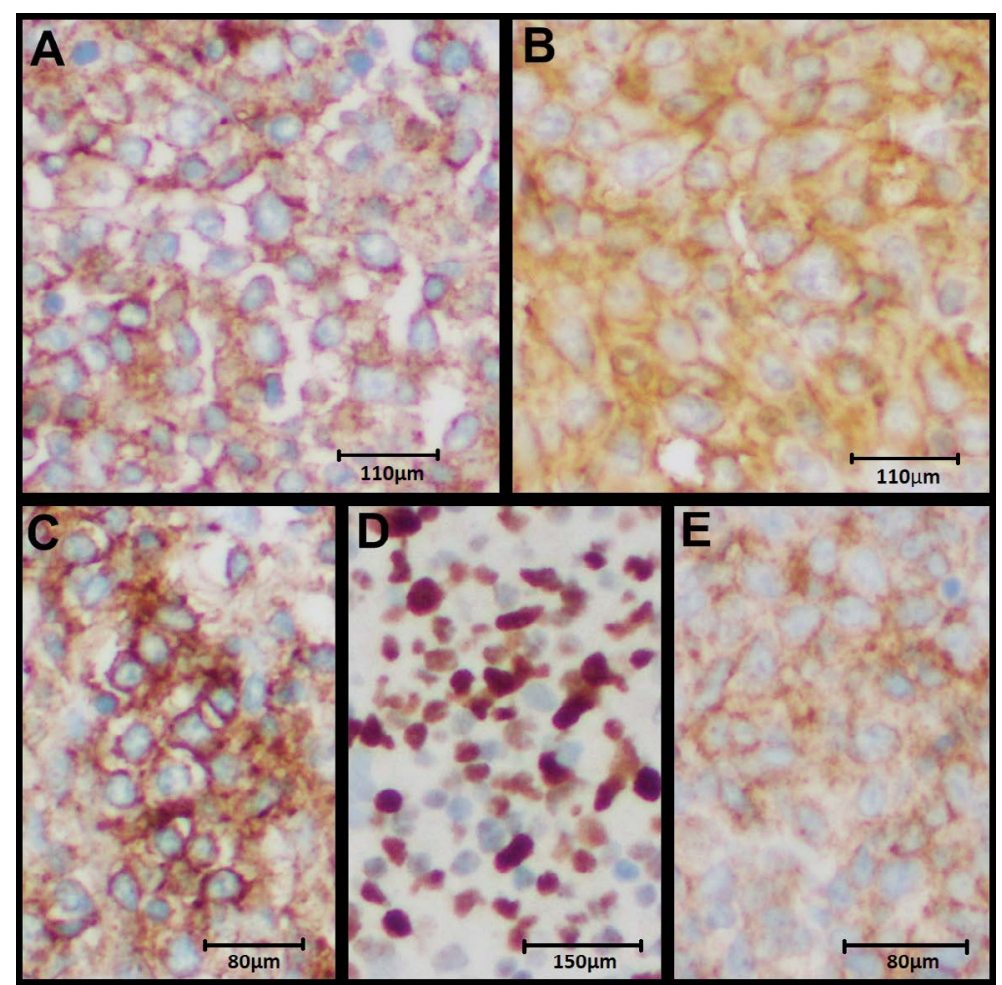

Figure 2: Immunohistochemical features: Tumor cells brightly illuminated with CD45 (A), CD20 (B), bcl-2 (C), bcl-6 (D) and CD10 (E).

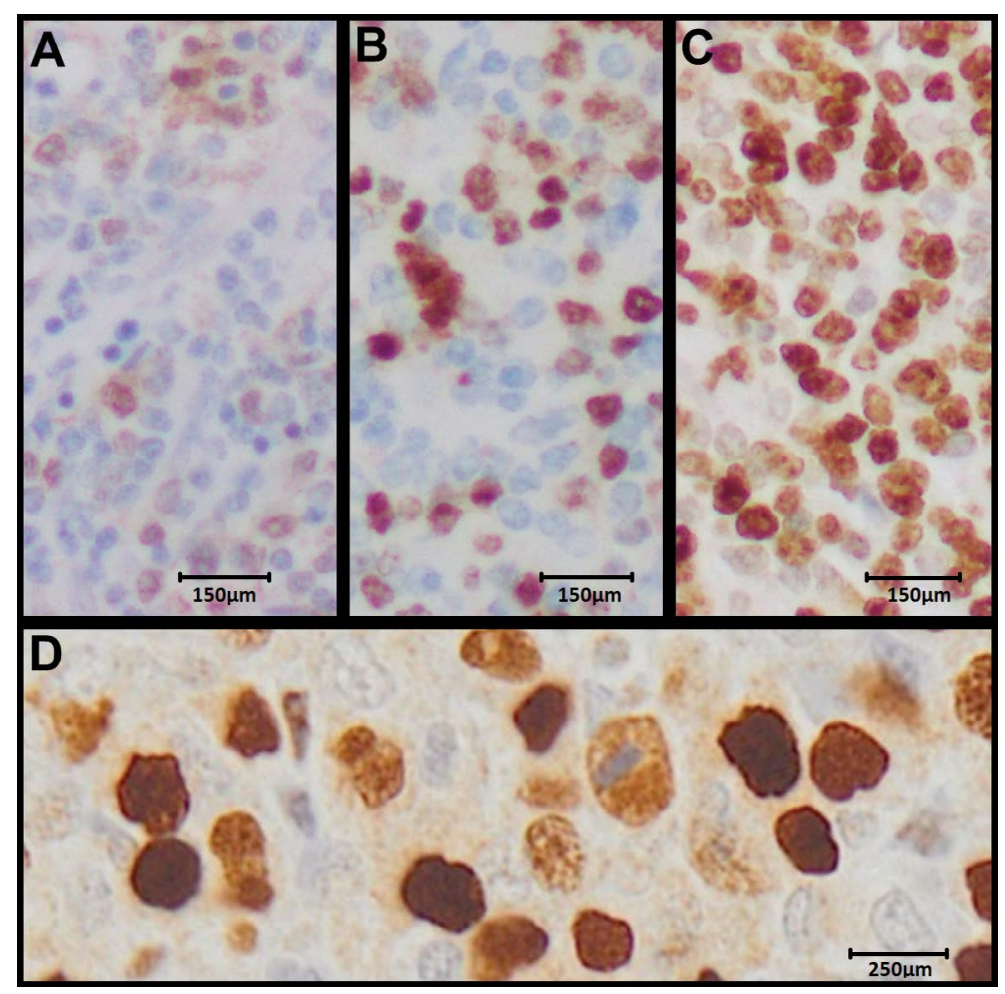

Figure 3: Additional ancillary tests: Patchy MUM-1 (A) immunopositivity. Nuclear and cytoplasmic c-myc staining in $>60 \%$ cells (B). Ki-67 (C) immunostaining in $>90 \%$ cells. Epstein Barr encoded, small RNA positivity (D). 


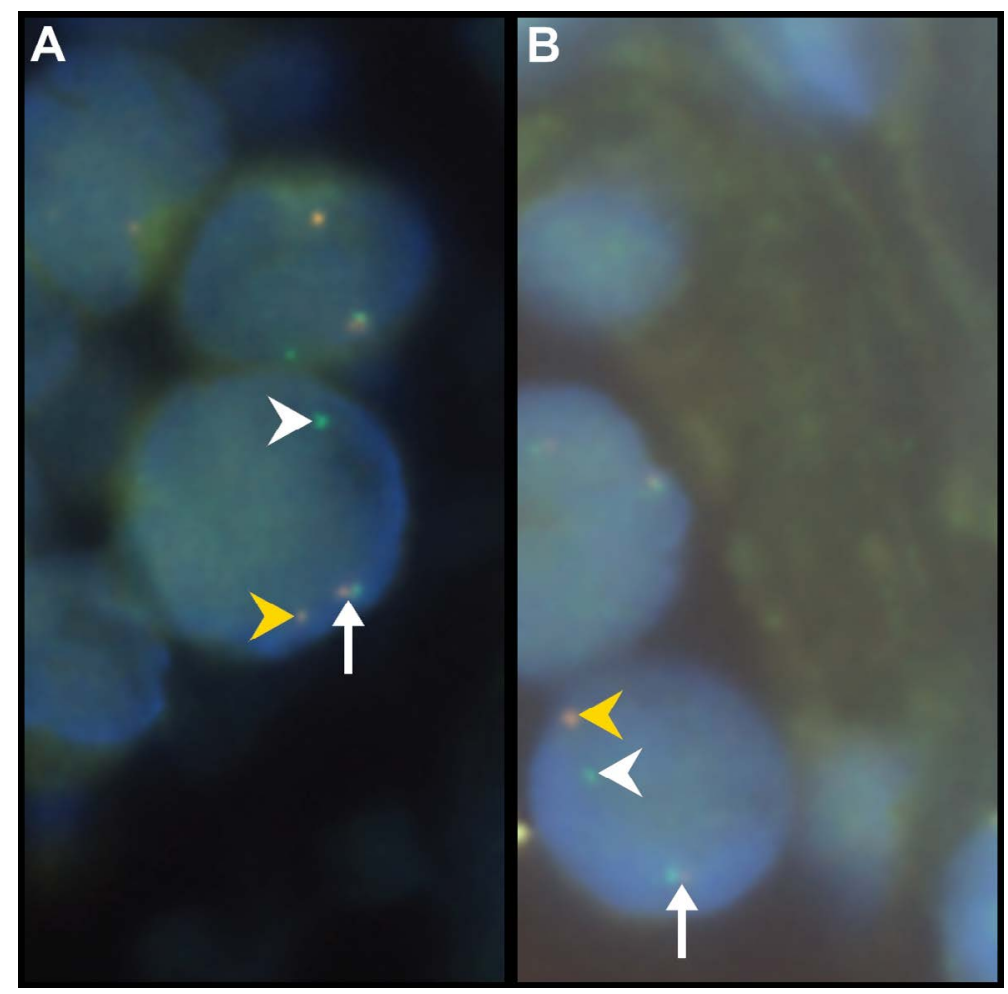

Figure 4: Fluorescent in situ hybridization investigation: MYC 8q24 (A) and BCL2 18q21 (B) chromosomal gene rearrangements on patient sample. The break apart signal pattern of $1 \mathrm{~F} 101 \mathrm{G}$ was observed in $M Y C$ and $B C L 2$ genes, depicted as one fusion signal (A, B: white arrow), one Spectrum Orange signal (A, B: yellow arrowhead) and one Spectrum Green signal (A, B: white arrowhead).

- Creation of a "HGBL, not otherwise specified (NOS)" category to shelter cases with morphological features intermediate between BL and DLBCL without MYC and BCL2 and/or BCL6 rearrangements.

Furthermore the 2016 WHO monograph also informs that DHL/ HGBL, with MYC and BCL2 and/or BCL6 rearrangements are not DLBCL with:

- MYC but not BCL2 or BCL6 rearrangements,

- Dual expression but not dual rearrangements of MYC and BCL2

- Amplifications or extra copies of MYC, BCL2 and BCL6 [2].

Accounting for $3-10 \%$ of DLBCLs, double and triple hit lymphomas are typified by aggressive clinical behavior [9], complex karyotypes and heterogeneous pathological characteristics that overlap with BL, DLBCL and B-lymphoblastic lymphoma [10]. The aggressive clinical course of DHL is typified by advanced disease stage with a high-intermediate or high International Prognostic Index, extranodal spread, including frequent bone marrow and CNS involvement and elevated serum lactate dehydrogenase levels $[3,4,10]$. Some studies have identified heightened gastrointestinal tract involvement $[3,10,11]$. HGBL, with MYC and BCL2 rearrangements is predominantly a disease of older male patients, with the median age at diagnosis ranging from 51 to 65 years $[10,12]$. Lymphoma is the third most common cancer in children; non-Hodgkin lymphomas (NHLs) account for $60 \%$ of this tumor type. However, the spectrum, management and outcome of NHLs in children differ from that of their adult counterparts. Specifically, the majority of NHLs in children is predominantly mature, aggressive B-cell lymphomas, of Burkitt and diffuses large B-cell subtypes, while indolent NHLs are more frequent in adults [13]. Furthermore, genomic and gene expression profiling have landscaped DLBCLs in adults as a heterogenous entity, while in children, they are predominantly homogenous, with a germinal centre immunophenotype and a lack of $\mathrm{t}(14 ; 18)$. HGBL, with $M Y C$ and $B C L 2$ or BCL6 rearrangements are reported rarely in young adults, adolescents and children [3-5]. Two children, aged 9 and 11 years, with HGBL with MYC/BCL6 aberrations are documented but HGBL with MYC and BCL2 translocations, are unreported in children, to date [5,14-17]. Similar to reported DHLs in adults, our patient had aggressive disease, a poor response to treatment and a fatal outcome. Although the index patient had a biologically aggressive malignancy, the impact of AIDS-related immunosuppression on the response to treatment and outcome of the disease should not be undermined.

Systemic NHL has been categorized as an AIDS-defining malignancy since 1985 [18] and remains the most common neoplastic cause of death in HIV-infected adult patients [19]. Prior to the introduction of HAART, AIDS-related non-Hodgkin lymphomas occurred 60-200 times more commonly in patients with AIDS patients than in HIVnegative individuals [20]. The advent of HAART not only effected a decreased incidence of AIDS-related NHLs but also underpinned improved patient survival attributed to decreased co-morbid infections, improved tolerance to chemotherapy and increased remission rates [21]. Notwithstanding the impact of HAART on AIDS outcomes, the risk of NHL remains elevated in the AIDS context [22]. Whilst the most common lymphomas in the HAART era are BL and DLBCL [23], the spectrum of HIV-associated lymphomas has expanded to include those that occur commonly in the general population and those that occur with heightened propensity in HIV-infected patients (Table 1) 
A. Lymphomas occurring more commonly in HIV-infected patients

1. Primary effusion lymphoma

- Including solid variant

2. Kaposi sarcoma herpes virus-associated multicentric Castleman diseaserelated large cell lymphoma

3. Plasmablastic lymphoma of the oral cavity type

B. Lymphomas also occurring in immunocompetent individuals

1. Hodgkin lymphoma

2. Non-Hodgkin lymphoma

- Burkitt lymphoma

- Diffuse large B-cell lymphoma

$$
\text { - Centroblastic }
$$

- Immunoblastic

- Including primary central nervous system lymphoma

- Extranodal marginal zone lymphoma of MALT type

- Peripheral T-cell lymphoma

C. Others

1. Lymphomas occurring in other immunodeficiency states

- Polymorphic B-cell lymphoma

2. Newly described lymphomas in HIV-infected patients

- Human herpesvirus-8 large T-cell lymphoma

3. This report

High grade B-cell lymphoma with MYC and BCL2 translocations

Table 1: Spectrum of HIV-associated lymphoma [23-26].

[23-26]. The latter include plasmablastic lymphoma of oral cavity type, Kaposi sarcoma (KS) herpes virus-associated Castleman diseaserelated large cell lymphoma and primary effusion lymphoma and its solid variants [23-25]. Furthermore, DLBCLs in immunocompetent patients are characterized either by germinal center or activated B-cell immunophenotypes, while AIDS-related DLBCLs are typified by an intermediate germinal center/activated B-cell immunophenotype [20].

In contrast to that in HIV-infected adults, B-cell NHLs are the most common malignancy in HIV-infected children [27]. There is little recent documentation on the course of NHLs in the HIV-infected pediatric population, with or without HAART $[20,27]$. Similar to the outcome in adults, HIV-infected children on HAART have improved tolerance to chemotherapy and better prognosis than in HAART-naïve HIV-infected patients [27]. In common with adults, pediatric NHLs are of systemic, CNS and effusion types [20,27]. The spectrum of systemic NHLs in children with AIDS includes BL, DLBCL and plasmablastic lymphoma $[27,28]$. Whether the rarity of DHLs in children is a true rarity or an under-investigated or under-reported phenomenon remains speculative, as detailed phenotypic, immunophenotypic and genotypic findings of AIDS-associated NHLs are documented rarely [28]. In the present patient, the mixed immunoblastic-centroblastic morphology, starry sky pattern, high Ki-67 proliferation index and intermediate germinal center-activated immunophenotype prompted C-MYC, BCL-2, BCL-6 and cyclin D1 FISH studies that revealed the "double hit" profile. In developing countries with high incidence of AIDS and associated high co-morbid states, optimal laboratory facilities are pivotal to accurate diagnoses, but financial constraints and the pressing need to treat more common infective conditions, may negatively impact the optimal resourcing of laboratories and laboratory personnel and lymphoma diagnostics. This requires redress, especially in the HAART era where, in contrast to KS that is associated with extreme immunosuppression, NHLs occur in children with relatively well-preserved immune systems [29]. The wide-spread availability of HAART in Africa has been possible through international assistance programmes [30]. A similar approach to improve laboratories in developing countries and/or remote consultation may be necessary to enable optimal work-up and diagnosis of NHLs and other AIDSassociated malignancies and their appropriate management.

The documented median survival time of patients with DHL is approximately 4 months from diagnosis [11]. Whilst this may represent an outcome of a biologically aggressive malignancy, there is also no established treatment protocol for DHL [2]. Furthermore, treatmentrelated issues and challenges of lymphomas are documented mainly for HIV-naïve adults. While radiotherapy and several chemotherapy regimens, including rituximab, cyclophosphamide, doxorubicin, vincristine and prednisone (R-CHOP), CODOX-M/IVAC regimens, and R-hyper CVAD/MA (rituximab, hyper fractionated cyclophosphamide, vincristine, doxorubicin, and dexamethasone, alternating with cytarabine plus methotrexate) and high-dose chemotherapy regimens with stem cell transplantation have been employed [7,14,31-34], there is high resistance to intensive chemotherapy and radiotherapy. This results in poor outcomes, including suboptimal complete response, event-free survival and overall survival. While our patient was treated with rituximab, cyclophosphamide, doxorubicin and methotrexate and appeared to respond thereto, disease relapse was rapid, reflecting not only the outcome of an aggressive malignancy but also potential AIDSassociated factors that may straddle the outcome of NHLs in general.

The factors impacting NHL outcomes include pre-existing bone marrow dysfunction, opportunistic infections and potential drugassociated interactions of the multidrug anti-retroviral regimes [29]. However, the improved patient tolerance for chemotherapy and related survival beyond two years on recommended short, drug-intensive regimens rather than prolonged intense treatment modalities, also provide a potential improved approach for DHLs in HIV-infected children, in particular $[29,35]$. The present patient was also treated with the anti-CD20 agent, rituximab. The use of rituximab in HIV-infected patients with NHLs has been debated, because of the associated increased risk of infectious deaths, a consequence of rituximab-induced B-cell depletion on a background of severe T-cell depletion $[27,36]$. Recent studies have highlighted the safety and efficacy of chemotherapy in combination with rituximab in patients with CD4 counts above 50 cells/ $\mu \mathrm{L}[27,36,37]$. The index patient had chemotherapy and rituximab following initial diagnosis and recurrence. Despite an initial good response, the patient did not tolerate the treatment of the recurrent disease. The lower CD4 count during the treatment of the recurrent disease supports the current recommendation that the caveat underlying the efficacy and safety of rituximab is the CD4 count [27,36-38].

Morphologically, DHLs/HGBCLs with MYC and BCL2 translocations are DLBCLs, but the immunophenotypic profile serves as a clue to potential double or multiple translocations on FISH studies; FISH is the gold standard for diagnostic confirmation of $>1$ translocation. Lymphomas with $C-M Y C$, bcl-2 and/or bcl-6 immunopositivity in the absence of FISH-confirmed translocations are categorized as doubleexpressor and not double hit lymphomas [1]. The morphological differential diagnosis includes large cell lymphomas with high grade features. In the AIDS context, plasmablastic lymphoma is a compelling differential diagnosis [28]. While the nuclei in the present tumor lacked the coarse, peripherally aligned, clockface chromatin of plasmacytoid cells and plasmablasts, the tumor was characterized by diffuse and starry sky patterns and high mitotic count, typical of plasmablastic lymphoma [28]. In contrast to DHLs, plasmablastic lymphoma contains plasmablasts and immunoblasts with abundant basophilic cytoplasm, nuclei with a prominent central nucleolus and paranuclear hof $[1,6]$. Immunophenotypically, plasmablastic lymphoma is a CD20-negative 
tumor while DHL is typically CD20-positive, but both lymphomas share a high Ki67 proliferation index and are commonly EBERpositive. Typical BL, similar to DHL, also demonstrates a prominent starry-sky pattern, high mitotic count, prominent apoptotic bodies and common EBER-positivity; in contrast to DHL, BL is composed mainly of intermediate sized cells with variably basophilic and vacuolated cytoplasm and nuclei with a fine chromatin pattern with multiple small nucleoli. Lymphoblastic lymphoma is a morphological mimicker but a negative terminal deoxynucleotidyl transferase immunoprofile and EBER positivity support DHL/HGBCL, with $M Y C$ and $B C L 2$ translocations.

\section{Conclusion}

HGBCL with MYC and BCL2 translocations is now a distinctive entity in the 2016 revised World Health Classification of lymphoid neoplasms [1]. This NHL is typified by DLBCL morphology and requires chromosomal translocation studies for its definitive diagnosis. In documenting the first HGBCL with MYC and BCL2 translocations in childhood and in AIDS, we re-affirm, similar to that in adults, the importance of chromosomal translocation studies, especially FISH investigation, on DLBCL samples, including those that are paraffinwax embedded, for diagnostic confirmation. The assessment of the initial biopsy, that did not include FISH investigation in its work-up, was that of a DLBCL with an intermediate germinal centre/activated B-cell phenotype. An initial favorable and subsequent fatal response to therapy was experienced when the CD 4 counts were $>500$ cells $/ \mu \mathrm{L}$ and $<200$ cells/ $\mu \mathrm{L}$, respectively. Robust ancillary investigation of DLBCL, irrespective of HIV status and age group, is necessary to confirm the prevalence of this NHL subtype, to better characterize its phenotypic and immunophenotypic features, to determine potential clues to $M Y C$ and $B C L 2$ translocations in the latter and to improve and standardize treatment guidelines. In the AIDS context, heightened diagnostic confirmation of "HGBCL with MYC and BCL2 translocations" underpins understanding of the impact of AIDS-immunosuppression on the response to treatment and disease outcome. While there are no established guidelines on whether all DLBCLs should be subjected to FISH or molecular studies, increased worldwide reporting of newly diagnosed and managed cases of this NHL in AIDS and non-AIDS settings is pivotal to improve global understanding and management of the disease in both clinical settings.

\section{References}

1. Swerdlow SH, Campo E, Pileri SA, Harris NL, Stein H, et al. (2016) The 2016 revision of the World Health Organization classification of lymphoid neoplasms. Blood 127: 2375-2390.

2. http://www.ascopost.com/issues/september-25-2015/double-hit-lymphomamany-treatment-strategies-no-standard-of-care

3. Li S, Lin P, Young KH, Kanagal-Shamanna R, Yin CC, et al. (2013) MYC/BCL2 double-hit high-grade B-cell lymphoma. Adv Anat Pathol 20: 315-326.

4. Li S, Seegmiller AC, Lin P, Wand XJ, Miranda RN, et al. (2015) B-cell lymphomas with concurrent MYC and BCL2 abnormalities other than translocations behave similarly to MYC/BCL2 double-hit lymphomas. Mod Pathol 28: 208-217.

5. Ahn JY, Seo YH, Park PW, Kim PH, Park MJ, et al. (2012) A case of B-cell lymphoma, unclassified, with features intermediate between diffuse large B-cell lymphoma and Burkitt lymphoma in a Korean child. Ann Lab Med 32: 162-166.

6. Campo E, Swerdlow SH, Harris NL, Pileri S, Stein H, et al. (2011) The 2008 WHO classification of lymphoid neoplasms and beyond: Evolving concepts and practical applications. Blood 117: 5019-5032.

7. Karube K, Campo E (2015) MYC alterations in diffuse large B-cell lymphomas. Semin Hematol 52: 97-106.

8. Cai Q, Medeiros LJ, Xu X, Young KH (2015) MYC-driven aggressive B-cell lymphomas: biology, entity, differential diagnosis and clinical management Oncotarget 17: 38591-38616.

9. Xu X, Zhang L, Wang Y, Zhang Q, Sun B, et al (2013) Double-hit and triplehit lymphomas arising from follicular lymphoma following acquisition of MYC Report of two cases and literature review. Int J Clin Exp Pathol 6: 788-794.

10. Snuderl M, Kolman OK, Chen YB, Hsu JJ, Ackerman AM, et al. (2010) B-cell lymphomas with concurrent IGH-BCL2 and MYC rearrangements are aggressive neoplasms with clinical and pathologic features distinct from Burkitt lymphoma and diffuse large B-cell lymphoma. Am J Surg Pathol 34: 327-340.

11. Tomito N, Tonunaka M, Nakamura N, Takeuchi K, Koike J, et al. (2009) Clinicopathological features of lymphoma/leukemia patients carrying both BCL2 and MYC translocations. Haematologica 94: 935-943.

12. Burotto M, Berkovits A, Dunleavy K (2016) Double hit lymphoma: From biology to therapeutic implications. Expert Rev Hematol 9: 669-678.

13. Klapper W, Stoecklein H, Zeynalova S, Ott G, Kosari F, et al. (2008) Structural aberrations affecting the MYC locus indicate a poor prognosis independent of clinical risk factors in diffuse large B-cell lymphomas treated within randomized trials of the German High Grade non-Hodgkin's Lymphoma Study Group (DSHNHL). Leukemia 22: 2226-2229.

14. Aukema SM, Siebert R, Schuuring E, van Imhoff GW, Kluin-Nelemans HC, et al. (2011) Double-hit B-cell lymphomas. Blood 117: 2319-2331.

15. Pillai RK, Sathanoori M, Van Oss SB, Swerdlow SH (2013) Double hit lymphomas with BCL6 and MYC translocations are aggressive, frequently extranodal lymphomas distinct from BCL2 double-hit B-cell lymphomas. Am J Surg Pathol 37: 323-332.

16. Rubnitz JE, Abushullaih B, Kaste SC, Raimondi SC, Sandlund JT, et al. (1998) BCL6 rearrangement and mediastinal involvement in a case of B cell acute lymphoblastic leukemia. Leukemia 12: 1163-1165.

17. Sandlund JT, Kastan MB, Kennedy W, Behm F, Entrekin E, et al. (2006) A subtle $t(3 ; 8)$ results in plausible juxtaposition of MYC and BCL6 in a child with Burkit lymphoma/leukemia and ataxia-telangiectasia. Cancer Genet Cytogenet 168: 69-72.

18. Miralles P, Berenguer J, Ribera JM, Rubio R, Mahillo B, et al. (2007) Prognosis of AIDS-related systemic non-Hodgkin lymphoma treated with chemotherapy and highly active antiretroviral therapy depends exclusively on tumor-related factors. J Acquir Immune Defic Syndr 44: 167-173.

19. Grulich AE, Vajdic CM (2015) The epidemiology of cancers in human immunodeficiency virus infection and after organ transplantation. Semin Oncol 42: 247-257.

20. Madan R, Gormley R, Dulau A, Xu D, Walsh D, et al. (2006) AIDS and nonAIDS diffuse large B-cell lymphomas express different antigen profiles. Mod Pathol 19: 438-446.

21. Diamond C, Taylor TH, Aboumrad T, Anton-Cluver H (2006) Changes in acquired immunodeficiency syndrome-related non-Hodgkin lymphoma in the era of highly active anti-retroviral therapy. Incidence, presentation, treatment and survival. Cancer 106: 128-135.

22. Gibson TM, Morton LM, Shiels MS, Clarke CA, Engels EA (2014) Risk of nonHodgkin lymphoma subtypes in HIV-infected people during the HAART era: A population-based study. AIDS 24: 2313-2318.

23. Carbone A, Volpi CC, Gualeni AV, Gloghini A (2017) Epstein-Barr virus associated lymphomas in people with HIV. Curr Opin HIV AIDS 12: 39-46.

24. Carbone A, Gloghini A (2005) AIDS-related lymphomas: from pathogenesis to pathology. Br J Haematol 130: 662-670.

25. Grogg KL, Miller RF, Dogan A (2007) HIV infection and lymphoma. J Clin Patho 60: $1365-1372$.

26. Pillay K, Hendricks M, Davidson A (2013) HHV-8 large T-cell lymphoma: An unusual malignancy amidst more common B-cell lymphomas in HIV-positive children treated at a single institution. J Pediatr Hematotol Oncol 35: e246-e248.

27. Godot C, Patte C, Blanche S, Rohrlich P, Dollfus C, et al. (2012) Characteristics and prognosis of B-cell lymphoma in HIV-infected children in the HAART era. J Pediatr Hematol Oncol 34: e282-e288.

28. Vaubell JI, Sing Y, Ramburan A, Sewram V, Thejpal R, et al. (2014). Pediatric plasmablastic lymphoma: A clinicopathologic study. Int J Surg Pathol 22: 607-616. 
Citation: Msimang MZ, Ramdial PK, Kuppusamy JB, Nargan K, Sheik-Gafoor MH (2017) AIDS-Associated Pediatric High Grade B-cell Lymphoma with MYC and BCL2 Translocations. J AIDS Clin Res 8: 742. doi: 10.4172/2155-6113.1000742

Page 7 of 7

29. Mueller BU (1999) Cancers in children infected with the human immunodeficiency virus. The Oncologist 4: 309-317.

30. Shiels MS, Engels EA (2017) Evolving epidemiology of HIV-associated malignancies. Curr Opin HIV AIDS 12: 6-11.

31. Kobayashi T, Tsutsumi Y, Sakamoto N, Nagoshi H, Yamamoto-Sugitani M, et al. (2012) Double hit lymphomas constitute a highly aggressive subgroup in diffuse large B-cell lymphomas in the era of rituximab. Jpn J Clin Oncol 42: 1035-1042.

32. Munoz J, Vekaria M, Hanbali A, Janakiraman N (2013) Progression of doublehit lymphoma in the midst of R-hyper CVAD. Am J Hematol 88: 87-88.

33. Peddi P, Gallagher KM, Chandrasekharan C, Wang Q, Gonzalez-Toledo E, et al. (2015) Tolosa-hunt syndrome in double-hit lymphoma. Case Rep Oncol Med 2015: 249891.
34. Pemmaraju N, Gill J, Gupta S, Krause JR (2014) Triple-hit lymphoma. Proc (Bayl Univ Med Cent) 27: 125-127.

35. Davidson A, Eley B (2010) HIV and childhood cancer. CME 28: 337-342.

36. Barta SK, Xue X, Wang D, Lee JY, Kaplan LD, et al. (2014) A new prognostic score for AIDS-related lymphomas in the rituximab-era. Haematologica 99: 1731-1737.

37. Boue F, Gabarre J, Gisselbrecht C, Reynes J, Cheret A, et al. (2006) Phase II trial of CHOP plus rituximab in patients with HIV-associated non-Hodgkin's lymphoma. J Clin Oncol 24: 4123-4128.

38. Sparano JA, Lee JY, Kaplan LD, Levine AM, Ramos JC, et al. (2010) Rituximab plus concurrent infusional EPOCH chemotherapy is highly effective in HIVassociated B-cell non-Hodgkin lymphoma. Blood 115: 3008-3016. 